\title{
Conceptual model for the integration of personal attribute skills in electrical technology education curriculum
}

\author{
Dahiru Sale Mohammed ${ }^{1}$, Sarimah Ismail ${ }^{2}$ \\ ${ }^{1}$ Department of Science and Technical Education, Faculty of Education, Northwest University Kano, State, Nigeria \\ ${ }^{2}$ School of Education, Faculty of Social Sciences and Humanities, Universiti Teknologi Malaysia, Malaysia
}

\begin{tabular}{l} 
Article Info \\
\hline Article history: \\
Received Aug 27, 2019 \\
Revised Oct 26, 2019 \\
Accepted Nov 25, 2019 \\
\hline
\end{tabular}

Keywords:

Conceptual model

Personal attributes

Technology education

TVET curriculum

\begin{abstract}
The current curriculum of Electrical Technology Education (ETE) of Nigerian Universities has been criticized for not meeting the desired challenges. The personal attribute skills were found are not integrated in the curriculum. Hence, a study was conducted to determine the types of personal attribute skills, their respective indicators and to develop a conceptual model for the integration of personal attribute skills for ETE curriculum. Mixed methods exploratory research design was employed for the study. 10 industry technical managers were interviewed and the interview data were analyzed using coding process of open coding, axial coding and selective coding. The interview data were used to develop a structured questionnaire that validated by 4 experts. Alpha value for pilot test was 0.89 . Sample of the survey were 646 including 528 ETE graduates, 22 ETE lecturers and 96 industry technical managers. Stepwise Linear Regression and Confirmatory Factor Analysis were used to analyze the survey. The study developed a conceptual model for the integration of personal attribute skills that consists of two major skills: attitude skills and trait skills. This study recommended the implementation of the conceptual model for the integration of employability skills in ETE curriculum.
\end{abstract}

Copyright $(\odot) 2019$ Institute of Advanced Engineering and Science. All rights reserved.

\section{Corresponding Author:}

Sarimah Ismail

Technical and Engineering Education Department,

School of Education, Faculty of Social Sciences and Humanities,

Universiti Teknologi Malaysia,

Johor Bahru, 81310 Skudai, Johor, Malaysia

Email: p-sarima@utm.my

\section{INTRODUCTION}

The Nigerian traditional educations were enriched with personal attribute skills. For example, personal attribute skills including spirituality, morality, ethics, integrity and honesty among others were taught in Northern Nigerian schools through the model of Imam Maliki School of Thought as result of holy war (Jihad) thar led by Sheik Usman Bin Fodio in 1804. Eventually the entire conquered area of Northern Nigeria acquired the personal attribute skills taught by the Sheik which became the culture of the Northern Nigeria [1].

Ironically, the Australian Chamber of Commerce and Industry (ACCI) and Business Council of Australian (BCA) have developed personal attribute skills within the Technical and Vocational Education and Training (TVET) training packages which was accepted and commissioned by Australian National Training Authority (ANTA) in 2002. The ACCI and BCA initiatives and development of employability skills was made by inclusion of personal attributes into Competency Based Training which was first introduced in Australia comprising knowledge, skills and personal attributes. The attributes were discarded in Australia until after they were included within the American Employability Skills definition. This has resulted in a very slow adoption rate of personal attribute skills in employability skills framework within the TVET [2] and 
most of the countries with similar technology approaches to Australia. To date personal attributes skills have discarded except superficial acknowledgment of the role of attributes in the curriculum [3].

Nigeria is one of the countries that adopted American Competency Based Training model that popularly known in the country as 6, 3, 3, 4 system of education in the 1980's [1] which has not been integrated with personal attribute skills except superficial acknowledgement in the National Policy on Education presently [4]. Personal attributes are good attitudes and traits of an individual that are used to get, maintain and succeed in employment [5]. The components of personal attributes skills identified from the literature were attitudes and traits [6-9].

The analytical review of ETE curriculum of Nigeria Federal Universities of Technology further indicates that the lack of incorporation of personal attributes course that directly teaches good attitudes and traits in the curriculum. The course of Nigerian People and Culture in the ETE curriculum is a course which has element of personal attributes with good attitudes and traits with main goal of the course is to learn different cultures of different tribes and ethnic groups for unity [10, 11].

The Nigerian higher education institutions failure in engineering education programmes including ETE has been related to continuous adherence to traditional teaching methods such as laboratory experimental method, lecture method, field trip method and project method during the final year in a university. The institutions did not integrate teaching employability skills including personal attributes needed by industries in their teaching methods [12].

The seven core employability skills needed in $21^{\text {st }}$ century identified were: technical, problem solving, collaboration, communication, information management, critical thinking and creativity while five personal attributes identified were: ethical awareness, cultural awareness, flexibility, self-direction and lifelong learning [13].

Because of high skilled workers who conceptualize knowledge, ideas and distribute information are highly needed by current industries, a large-scale survey among working professionals within industries was conducted. The findings indicated that the level of employability skills including personal attributes like social training and support varies considerably and therefore, each skill require unique developmental approach [14]. Qian and Clark [15] found game-based learning approach might be effective in facilitating students' personal attribute skill development. van Laar E. [16] found the relationships between components of employability skills and concluded that all employability skills including personal attributes skills lead to problem-solving skills. The results confirm that the analyzed skills were built on each other sequentially.

Background of this study discussed the gap in the integration of personal attribute skills courses that directly teaches good attitudes and traits and the conceptual model of personal attribute skills in ETE Bachelor Degree Curriculum. As a result, graduates of ETE programme has high percentage of unemployment [17] that might be due to lacking of employability skill of personal attribute skills needed by the industries. The ETE programme also has no conceptual model for the integration of personal attribute skills.

\section{LITERATURE REVIEW}

In 2004, a study was conducted by [6] to find out the discrepancies between perceptions of industry technical managers and higher education institutions on the importance of employability skills that graduates possessed when entering workplace and their success in the place of work. The data was collected through random sampling techniques from university heads of department and industry technical managers across the United States. Finding of the study indicated that industry technical managers rated six out of 12 employability skills as very important while heads of departments ranked only two employability skills as very important. The agreed skills between industry technical managers and higher education institutions are attitudes (integrity) and traits (ethics). While the discrepancies between the industry technical managers and higher educations are perseverance, adaptability, life skills and leadership skills.

An empirical study was conducted on 45 managers that have five different job functions in six industries in Malaysia, which are customer service, administrative, marketing, finance and accounting, and human resource. The industries involved were hypermarket, insurance, telecommunication, banking, manufacturing, and accounting. All respondents have been involved in the recruitment for job candidates in their respective job functions and industries, with average of 3.84 years of recruitment experience. $90 \%$ of the managers have been involved in setting the job requirement and job description for a particular position, conducting job interview and pre-employment tests, as well as deciding on selection and employment. Findings revealed that being responsible, adaptable and decent attitude with $60 \%, 40 \%$ and $40 \%$ respectively are the most important personal attributes industry technical managers when it comes to employment in Malaysia. Pearson Chi-square tests demonstrate that these attributes are not statistically associated to both industry and job position, indicating that they are needed in all industries and jobs in the country [9]. 
Empirical studies on the banking and financial service industries underscore the need for both technical skills and personality traits explicitly and implicitly. As observed by [18], there has been increasing demand for IT skills in the financial services sector, such as banking to improve the capacity of back-office systems in handling unexpected trading activities. However, personality traits like loan managers level of motivation are found to have lower influence on bad loans in banks [19].

Some personal attributes such as respectful, confidence, independence and efficiency are statistically associated to both job position and industry, indicating that they are varied by industries. For instance, $83 \%$ of managers in telecommunication and $50 \%$ of insurance industries expressed the confidence at work as important personal attribute. This may be due to the nature of the business in telecommunication and insurance industries where applications of confidence in handling potential customers and job tasks are highly valued [9].

Number of personal attributes are specific to job positions including cooperative among co-workers, self-awareness of own appearance, being patient, adventurous, and taking initiative. $67 \%$ of human resource managers valued cooperation among co-workers as the most important personal attribute which is opposite to customer service and marketing managers. This may be due to administrative nature of job functions in human resource department which requires cooperation among co-workers and teamwork within the same department and across different departments within the same organization. This differs with the nature of job tasks customer service and marketing staff that often deal with one customer at a time. The customers prefer to be followed up by the same staff that started convincing them. However, marketing managers emphasized attributes on marketers including appearance and being courageous with 56\% and 33\% respectively [9].

Another study revealed the importance of affective traits and practical skills among plant managers including interpersonal behaviors and managerial processes (Smith et al., 2009). For instance, aesthetic and social skills are considered more important than technical skills in interactive service work. These skills must be understood by the interactive service workers to improve their emotions intentionally for quality service [20].

Job applicants' personal attribute is regarded determinant of selecting university graduate for employment by industry technical managers in Malaysia. For instance, $60 \%$ of them highlighted the importance of personal attribute, and the evidence from the Pearson Chi-square revealed that the skill is generically required across industries but specifically differed by job positions. Personal attributes were highly valued by all administrative managers including marketing managers $67 \%$ while accounting and finance managers had 33\%. Other personal attributes needed for holding administrative positions are punctuality, being responsible, self-control and good attitude while good marketers required skills of appearance and quality of being confident [9].

Personal attribute skills were slowly adopted into the TVET training packages by Australian National Training Authority (ANTA) in 2002 comprising knowledge, skills and personal attributes because the attributes were thrown out in Australia until after they were incorporated within the American Employability Skills framework within the industry and most of the countries with similar technology approaches to Australia have to date avoided anything more than insincere recognition of the role of personal attributes in the employability skills into Competency Based Training packages [3].

Findings of a study indicate attitude with $56 \%$ as the main cause of fresh university graduates to be unsuccessfully employed as perceived by managers in Malaysia, followed by English communication skill (36\%) and work experience (31\%). These findings were totally agreed by managers from different industries and job positions. Lack of working experience may be due to the fact that they have just graduated while lacking of good English communication skill may be the consequence of the graduates' choice of medium of communication during their course in the university [9].

\section{METHOD}

There are three methods for choosing a research design which are quantitative method for post positivists, qualitative method for constructivists and mixed methods research for pragmatists [21]. The selection of those research methods are based on personal experience of the researcher, audience to whom the researcher reports his research and match between research questions and the methods [22]. Exploratory Sequential research design was adopted for this study because of the match between the research questions and methods. The qualitative method was employed to answer the first research question while the quantitative method was to answer second research question of the study. The results of both methods were used for the conceptual model development. 10 industry technical managers were interviewed. Member checking technique was adopted and determined the reliability of interview results in the study, Member checking refers to taking the transcribed data back to participants to review and confirm the credibility of the data and accuracy of the narrative description [23]. In this study, member checking was done by handing the 
interview transcript to the interviewed participants (industry technical managers). The managers checked against correctness of the data reported in the interview transcript in relation to their interview sessions.

The results of the qualitative method were used to produce structured questionnaire. Four research experts were validated the questionnaire. Draft version of the questionnaire was administered by 7 lecturers, 27 graduates and 5 industry technical managers with the reliability value of alpha cronbach of the questionnaire was $=.854$ This alpha coefficient indicated that the questionnaire possessed strong reliability. The total sample for the survey was 646, which included 96 industry technical managers, 22 ETE lecturers and 528 ETE graduates. The statistical method of stepwise linear regression and confirmatory factor analysis were used to analyze the survey. The survey results were used for the development of a conceptual model of the integration of personal attribute skills in ETE curriculum.

\section{RESEARCH AND DISCUSSION}

\subsection{Types and indicators of personal attribute skills}

The interview with industry managers perceived two types of personal attributes skills consisting of attitude skills and trait skills for ETE curriculum integration were identified from the opinions of industry with the indicators as explained below:

\subsection{1. $\quad$ Attitude skills}

This study found attitude skills as understandings and applications of integrity skills including selfdiscipline, commitment, honesty, responsibility, enthusiasm, reliability and high morality skills. Four industry technical managers of the companies stated:

Personal attributes skills are abilities to have keenness and interest to work hard, authenticity and veracity to perform a job as well as abilities to be consistent and dedicated in achieving goals of the organizations (Manager One).

Personal attributes skills are abilities attitude skills including abilities to be reliable, credible, trustworthiness upright and rectitude to work with little supervision in the company (Manager Three).

These findings explained personal attribute skills similar to attitude skills which are accountability, self-discipline, cooperation, need to do well, high morality, optimism, confident, loyalty, commitment, honesty, responsibility, enthusiasm, reliability and integrity.

\subsubsection{Traits skills}

This study found traits skills as understandings and applications of ethical skills including hardworking, punctuality, entrepreneurial mind, and well-dressing skills. Five industry technical managers of the companies stated:

Personal attributes skills are abilities to be painstaking, thorough and meticulous in achieving objectives of the company; abilities to be timekeeping, regularity and promptness in the place of work as well as abilities to be welcoming, approachable and open with other staff" '(Manager Two)

Personal attributes skills are abilities to have commercial, risk taking and innovative mind for effective improvement in the place of work in addition to abilities to have vision, originality, inventiveness, resourcefulness and inspirations to deal with human and materials problems in the company." (Manager Three).

Personal attributes skills are abilities to be energetic, dynamic and go-ahead to work well for progress in the field of employment as well as abilities to have balanced character, behaviour and temperament in the place of work in the company" (Manager Five)

These findings explained personal attribute skills similar to traits skills which are being patient at work, diligent, promptness, balanced personality, courtesy, sincerity, work with good manner, work with principle, approachable staff, well-dressed, creativity, and hardworking. The interview findings were summarized and presented in Table 1 . 
Table 1. Sumary of ypes and indicators of personal skills

\begin{tabular}{cl}
\hline Types & \multicolumn{1}{c}{ Indicators } \\
\hline Attitude Skills & $\begin{array}{l}\text { Accountability, Self-Discipline, Cooperation, Need to do Well, High Morality, Optimism, Confident, Loyalty, } \\
\text { Commitment, Honesty, Responsibility, Enthusiasm, Reliability and Integrity }\end{array}$ \\
Traits Skills & $\begin{array}{l}\text { Being Patient at Work, Diligent, promptness, balanced personality, Courtesy, Sincerity, work with good manner, } \\
\text { work with principle, approachable staff, Being Patient at Work, Well-Dressed, Creativity, and Hardworking. }\end{array}$ \\
\hline
\end{tabular}

\subsection{The best indicators of personal attribute skills}

The survey data were first subjected to Stepwise Linear Regression (SLR) of SPSS version 22 computer software and second SLR results were confirmed by using Confirmatory Factor Analysis (CFA) of AMOS computer software.

\subsubsection{SLR analysis}

The SLR results determined the best themes and best indicators of personal attribute skills for the integration into ETE curriculum. The results of SLR were summarized and presented in Table 2.

Table 2. The best indicators of personal attribute skills for ETE curriculum

\begin{tabular}{ll}
\hline \multicolumn{1}{c}{ Types } & \multicolumn{1}{c}{ Best Indicators } \\
\hline Attitude Skills & Honesty, High Morality, Reliability, Commitment, Integrity, Self-Discipline, and Responsibility \\
Traits Skills & Being Patient at Work, Well-Dressed, Creativity, Sincerity, Courtesy and Hardworking \\
\hline
\end{tabular}

\subsubsection{CFA analysis}

$1^{\text {st }}$ Step: Initial model of personal attributes skills before calculation of the data

The initial model of personal attribute skills was selected by Stepwise Linear Regression method. The types of personal attribute skills in AMOS are called factors which include attitude skills and trait skills. The best indicators of each type are known in AMOS as observe variables and their errors known in AMOS as latent variables. The observe variables of personal attitude were the seven best indicatorss of attitudes for ETE Curriculum Integration by the ETE graduates, ETE lecturers and industry technical managers consisting of honesty (PAS1), high morality (PAS2), reliability (PAS3), commitment (PAS4), integrity (PAS5), selfdiscipline (PAS6), and responsibility (PAS7). The observe variables of trait skills were being patient at work (TRS1), well-dressed (TRS2), creativity (TRS3), sincerity (TRS4), courtesy (TRS5) and hardworking (TRS6). These observe variables and their respective latent variables were shown in Figure 1.

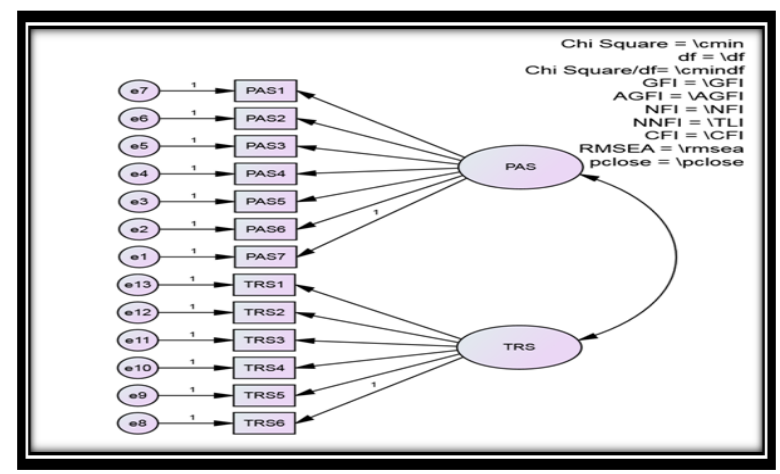

Figure 1. Initial model of personal attributes skills before calculation of the data

$2^{\text {nd }}$ Step: First calculation and inspection of factor loading to remove problematic variables

The data was first calculated in the initial model of personal attributes, the factor loading of attitude skills of $0.34,0.30,0.28,0.33,0.69,0.77$ and 1.00 for honesty (PAS1), high morality (PAS2), reliability (PAS3), commitment (PAS4), integrity (PAS5), self-discipline (PAS6), and responsibility (PAS7) respectively and the factor loading of traits skills of 1.90, 1.96, 1.42, 1.47, 1.57 and 1.00 for being patient at work (TRS1), well-dressed (TRS2), creativity (TRS3), sincerity (TRS4), courtesy (TRS5) and hardworking (TRS6) respectively were found. The model did not meet the criterion of standardized model fitness where the chi square/degree of freedom $=12.854$, GFI=0.751, AGFI=0.646, NFI=0.642, NNFI $=0.583, \mathrm{CFI}=0.658$, 
RMSEA $=0.169$ and pclose $=000$. This decision was based on the model fit indices found in the initial model of personal attribute skills. However, to ascertain good model fit of personal attributes, a logical trimming of the model deemed necessary by removal of possible problematic observe variables (elements) with low factor loading that might have caused poor fit of the initial model. These problematic variables that were gradually removed as a result of low factor loadings consist of PAS1, PAS2, PAS3 and PAS

\section{$3^{\text {th }}$ Step: Second calculation of data and inspection of covariance to improve model fit}

The First Improved Model of Personal Attribute Skills was calculated again in AMOS. The model factor loadings were improved where the factor loading of attitude skills of 0.77, 0.90 and 1.00 for PAS5, PAS6 and PAS7 respectively and the factor loading of traits skills of 1.85, 1.94, 1.42, 1.47, 1.59 and 1.00 for TRS1, TRS2, TRS3, TR 4, TRS5, TRS5, TRS6 and TRS7 respectively were found.

The First Improved Model of Personal Attribute Skills fit indices were improved but did not meet the criterion of standardized model fitness that the chi square/degree of freedom $=14.126$, GFI $=0.845$, AGFI $=0.732, \mathrm{NFI}=0.786, \mathrm{NNFI}=0.719, \mathrm{CFI}=0.797, \mathrm{RMSEA}=0.178$ and pclose $=000$. The $4^{\text {th }}$ stage was the inspection of covariance to deal with covariance between errors of the same construct (factor).

The inspection of the AMOS output Modification Indices (MI) revealed that e2<-->e3, e10<-->e11 and $\mathrm{e} 8<-->\mathrm{e} 11$ had the highest MI at their respective factors. This statistics necessitated for their covariance. The inspection of the AMOS output fit indices revealed that the best model fit was not achieved that the chi square/degree of freedom=5.124, GFI=0.941, AGFI=0.884, NFI=0.931, NNFI=0.912, CFI=0.944, RMSEA $=0.100$ and pclose $=000$ as shown in Figure 2.

\section{model fit}

$4^{\text {th }}$ Step: Third calculation and inspection of standardized residual covariance to improve

Since the variables cannot be further trimmed or co-varied, the final stage was the inspection of standardized residual covariance to find and remove the variables with bigger absolute values above 2.4. The variable which has the highest value of standardized residual covariance found was TRS4 as shown in Table 2. The TRS4 was removed from the First Improved Model of Personal Attribute Skills and calculated in Amos. Here the standardized model of personal attribute skills was confirmed after meeting the criteria for model fit indices that the chi square/degree of freedom=4.319, GFI=0.958, AGFI=0.911, NFI=0.948, $\mathrm{NNFI}=0.932, \mathrm{CFI}=0.959$, RMSEA $=0.089$ and pclose $=001$. The model indicated that the value of chi square/degree of freedom was between 5 and 2 indicating excellent fit, RMSEA was between 0.081 to 0.090 which indicates very good fit and GFI, AGFI, NFI, NNFI and CFI were above 0.900 indicating excellent fit.

The model confirmed two constructs of Personal Attributes skills and their observe variables of attitude skills with integrity skills (PAS5), self-discipline skills (PAS6) and responsibility skills (PAS7) and the traits skills (TRS) with being patient at work skills (TRS1), well-dressed skills (TRS2), creativity skills (TRS3), courtesy skills (TRS5) and hardworking skills (TRS6) for ETE curriculum integration by graduates, ETE lecturers and industry technical managers.

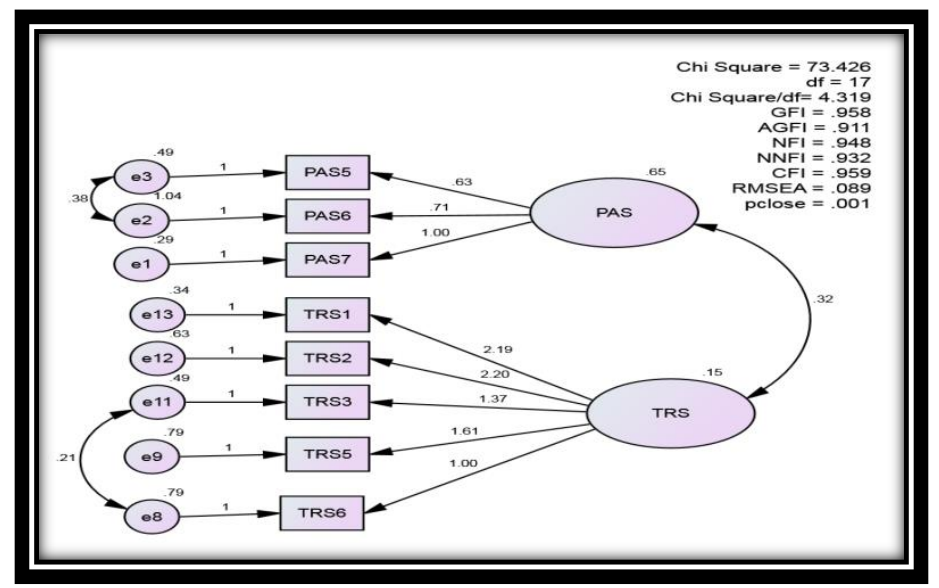

Figure 2. Standardized model of personal attribute skills 


\subsection{Conceptual model for the integration of personal attribute skills in ETE curriculum}

Based on the standardized model of personal attribute skills which was confirmed from the confirmatory factor analysis, the conceptual model for the integration of personal attribute skills into electrical technology education curriculum was constructed as shown in Figure 3.

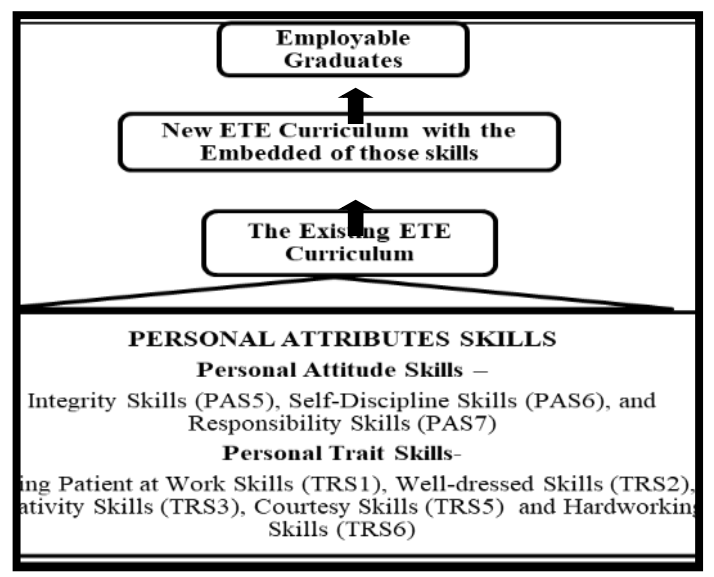

Figure 3. Conceptual model for the integration of personal attribute skills in ETE curriculum

Personal attribute skills refer to set of skills for individual qualities of attitudes and traits, perseverance, adaptability, life skills and leadership skills [6], responsible, adaptable and decent attitude [9]. The standardized model of personal attribute skills confirmed two constructs: personal attitudes skills (PAS) and traits skills (TRS).

Personal attitudes skills refer to ability of being true to words that demonstrate good behavior for others to copy, being authentic in speech and actions even under stress because of enormous benefit to derive from it [24]. Conceptual model of this study confirmed three best indicators of PAS which are integrity skills (PAS5), self-discipline skills (PAS6) and responsibility skills (PAS7).

Traits are ethical values that should include more than familiarization of professional codes of conduct and machinery for enforcing them, students must be aware that traits skills are instrument that affect the quality of life [25]. This study found five best indicators of TRS including being patient at work skills (TRS1), well-dressed skills (TRS2), creativity skills (TRS3), courtesy skills (TRS5) and hardworking skills (TRS6) for ETE curriculum integration by graduates, ETE lecturers and industry technical managers. The Figure 3 showed the Standardized Model of Personal Skills after calculating the data for Confirmatory Factor Analysis in AMOS computer software.

\section{CONCLUSION}

The personal attribute skills were rejected in Australian education model for TVET until after they were incorporated in USA and up to today, most of the nations with comparable technology approaches to Australia have rejected the integration of personal attributes in their education model for TVET. Nigeria adopted American education model for TVET and that rejected her personal attribute skills like Australia. The above literature highlighted the lack of integration of personal attribute skills in TVET Curriculum. This study found the specific personal attribute skills required by industry managers for the integration ETE curriculum and the conceptual model of personal attribute skills that can guide its implementation. This is to ensure the skills possessed by ETE graduates of Nigeria Federal Universities of Technology are relevant to industry for the graduates' employments and to save cost of further training of the ETE graduate that employed by the industry.

\section{REFERENCES}

[1] Fafunwa, A. B, "History of education in Nigeria," London: George Allen and Unwin, 2004.

[2] Kerka, "Competency-based education and training ERIC clearinghouse on adult, career and vocational education: $2, " 1998$.

[3] Down, C. "Employability skills: Revisiting the key competencies or a new way forward?," Retrieved on 16/06/2012 from http://www.docstoc.com/docs/52545372/Employability-Skills-Revisiting-the-Key-Competencies-or-a-new, 2012. 
[4] FGN (Federal Government of Nigeria), "National policy on education (4thed)," Abuja: Nigeria Educational Research and Development Council Publishers. ISBN-978-054-7, 2014.

[5] Zaharim, A., Yusoff, Y. M., Muhammed, A., Omar, M. Z., Muhammad, N. and Mustapha R., "practical framework of employability, skill for engineering graduate in Malaysia," IEE EDUCON Education Engineering, 2010 - The future of global learning engineering education, Madrid Spain on April 2010 pp. 921-927, 978-1-42 44-657 12/10/828.00@2010IEEEs.

[6] Shivpuri, S and Kim, B., "Do employers and colleges see eye-to-eye?," National Association of Colleges and employers, pp. 37-44, 2004.

[7] Singh, G. K. G and Singh, S. K. G., "Malaysian graduate employability skills," UNITAR E-Journal, vol. 4(1), pp. 15-45, Jan 2008.

[8] Buntat, Y., Jabor, M. K., Saud, M. S., Mansor, S. M. S. S. and Mustaffa, N. H., "Employability skills element's: difference perspective between teaching staff and employers industrial in Malaysia," Procedia - Social and Behavioral Sciences, vol. 93, pp. 1531-1535, 2013.

[9] Wye, C. K. and Lim, Y. M., "Analyzing skill profile among business graduates: Is it generic or specific?," International Journal of Business, Economics and Management, vol. 1(5), pp. 57-71, 2014.

[10] Mohammed, D. S and Ismail, S., "The needs for employability skills integrations in electrical technology education curriculum of Federal Universities of Technology in Nigeria," Conference proceedings of the 4th World Congress on TVET 2014, held at Equaterial Hotel, Melacca, Malaysia on 5th and 6th December, 2014.

[11] Ismail, S and Mohammed, D. S., "Employability skills in TVET curriculum in Nigeria Federal Universities of technology," Procedia - Social and Behavioral Sciences, vol. 204, pp. 73-80, 2015.

[12] Terungwa S. A., Subari, K., Jambari, H., Muhammad Noordin, M. K., Onyilo, I. R., "Engineering and related programs' teaching methods in Nigeria," International Journal of Recent Technology and Engineering (IJRTE), vol. 8(2), Jul 2019.

[13] Van Laar, E., Van Deursen, A. J. A. M., Van Dijk, J. A. G. M., \& de Haan, J., "The relation between 21st-century skills and digital skills: A systematic literature review," Computers in Human Behavior, vol. 72, pp. 577-588, Jul 2017.

[14] Van Laar, E., Van Deursen, A. J. A. M., van Dijk, J. A. G. M., \& de Haan, J., "Determinants of 21st-century digital skills: A large-scale survey among working professionals," Computers in Human Behavior, vol. 100, pp. 93-104, Nov 2019.

[15] Qian, M. and Clark, K. R., "Game-based learning and 21st century skills: A review of recent research," Computers in Human Behavior, vol. 63, pp. 50-58, Oct 2016.

[16] van Laar, E., van Deursen, A. J. A. M., van Dijk, J. A. G. M., \& de Haan, J., "The sequential and conditional nature of 21st-century digital skills," International Journal of Communication, University of Southern Carlifornia, vol. 13, 2019.

[17] NBS (National Bureau of Statistics), "Labour force statistics vol. 1: Unemployment and underemployment report," Abuja: NBS Publication, Available at www. Nigeriastat.gov.ng, 2017.

[18] Thomson, R., "Demand for IT skills rising as credit crunch shows flaws in bank systems," Computer Weekly, pp. 41, 2007.

[19] Sanjeev, G.M., "Bankers' perceptions on causes of bad loans in banks," Journal of Management Research, vol. 7(1), pp. 40-46, 2007.

[20] Thompson, P., Warhurst, C., Callaghan, G., "Ignorant theory and knowledgeable workers: Interrogating the connections between knowledge, skills and services," Journal of Management Studies, vol. 38(7), pp. 923942, 2001.

[21] Creswell, W. J., "Educational research: Planning, Conducting and Evaluating Quantitative and Qualitative Researches (4th ed.)," Boston: Pearson Education Inc, 2012.

[22] Creswell, W. J., "Research design: Qualitative, quantitative and mixed methods approaches (3rd ed.)," Thousand Oaks, California: SAGE publications. Inc, 2009.

[23] Lincoln, Y. S., and Guba, E. G., "Naturalistic inquiry," Beverly Hills, CA: Sage, 1985.

[24] MTD Training, "Personal confidence and motivation," U. K: Ventus Publishing APS, 2010.

[25] Maughan, C. and Webb, J., "Lawyering skills and the legal process (2nd ed)," Cambridge: University Press, 2005. 